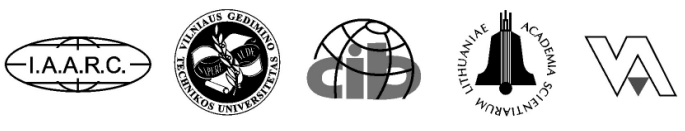

Institute of Internet and Intelligent Technologies

Vilnius Gediminas Technical University

Saulètekio al. 11, 10223 Vilnius, Lithuania

http:/www.isarc2008.vgtu.lt/
The $25^{\text {th }}$ International Symposium on Automation and Robotics in Construction

June 26-29, 2008

ISARC-2008

\title{
INTEGRATED TUNNEL MONITORING SYSTEM USING WIRELESS AUTOMATED DATA COLLECTION TECHNOLOGY
}

\author{
Jung-Ryul Kim \\ Researcher \\ KICT, 2311, Daehwa- \\ dong, Ilsanseo-gu, \\ Goyang-si, Gyeonggi- \\ do, 411-712, \\ South Korea \\ jrkim@kict.re.kr
}

\author{
Hyun-Suk Yoo \\ Researcher \\ KICT, 2311, Daehwa- \\ dong, Ilsanseo-gu, \\ Goyang-si, Gyeonggi- \\ do, 411-712, \\ South Korea \\ hsyoo@kict.re.kr
}

\author{
Soon-Wook Kwon \\ Professor \\ Sungkyunkwan Univ., \\ 300 Cheon-cheon-dong, \\ Jangan-gu, Suwon, \\ Gyeonggi-do, 440-746, \\ South Korea \\ swkwon@skku.edu
}

\author{
Moon-Young Cho \\ Research Fellow \\ KICT, 2311, Daeh-wa- \\ dong, Ilsanseo-gu, \\ Goyang-si, Gyeonggi- \\ do, 411-712, \\ South Korea \\ mycho@kict.re.kr
}

\begin{abstract}
Tunnel accident is apt to become a serious disaster when it occurs. But tunnel construction is being increased rapidly in Korea because tunnel has advantages and usefulness. According to Korean Ministry of Land, Transport and Maritime Affairs, total length of road tunnels was extended from $150 \mathrm{~km}$ to $648 \mathrm{~km}$ for last decade (333\% increased). On the other hand there are several tunnels aged about 100 years. Therefore systematic health monitoring is necessary to these old and new tunnels during their life time. But conventional tunnel management systems in Korea have several limitations. First, they were made for each tunnel on a case by case and not integrated totally. Second, they are uncomfortable to use because they used wire based sensors and non-graphic user interface. So we developed integrated tunnel monitoring system using wireless and automated data collection, 3D CAD system. We used system modularization technology to integrate and apply various tunnels, Zigbee technology to collect data and Korean 3D technology to display sensing values. This paper describes framework and prototype of this system.
\end{abstract}

\section{KEYWORDS}

Tunnel, ADC, Monitoring, Zigbee, Wireless Communication

\section{INTRODUCTION}

Tunnel is playing an important role in terms of environmental and economic aspects when constructing national road network in hilly South Korea. By this reason, tunnel construction in Korea has been increased rapidly and according to Ministry of Land, Transport and Maritime Affairs, number of tunnels having been constructed for the past 10 years shares $59 \%$ of the total one. In addition, total length of road tunnel was extended rapidly from $150 \mathrm{~km}$ to $648 \mathrm{~km}$ by $333 \%$. On the other hand, there are several tunnels aged almost 100 years [1]. Therefore, operation and maintenance through systematic 
monitoring techniques is prerequisite for these old and new tunnels during their life cycle time. But conventional tunnel management systems in Korea have several limitations. First, they were made for each tunnel on a case by case and not integrated totally. Second, they are uncomfortable to use because they used wire based sensors and nongraphic user interface. So we developed integrated tunnel monitoring system using wireless and automated data collection, 3D CAD system. We used system modularization technology to integrate and apply various tunnels, Zigbee technology to collect data and Korean 3D cad system to display sensing values. This paper describes framework and prototype of this system.

\section{RESEARCH TRENDS}

\subsection{Deformation Monitoring Techniques}

In this study, currently existing diversified deformation monitoring techniques is being addressed [2].

First, tunnel wall deformation is usually measured with tape extensometers, geodetic surveying (total stations) and laser scanners (profilometers).

Laser scanners (or tunnel profilometers) are recent development in measuring the geometry of tunnel walls in cross-section. A typical system shown in Figure 1 consists of two closed-circuit digital (CCD) cameras mounted on a portable frame [3]. The position of the camera frame is automatically determined by a total station with automatic target recognition placed up to a maximum distance of 100 $\mathrm{m}$. For this purpose, three reflector targets are permanently mounted on the frame. Digital images are automatically stored in a computer and can be processed to provide the 3D coordinates of the surveyed tunnel wall surface with an accuracy of F5 $\mathrm{mm}$ for each coordinate. Although this level of accuracy is low compared to routine geodetic surveying, the advantage of recording a very large number of points on the tunnel wall can outweigh the low accuracy for many applications.

Second, deformation measurements at ground surface, structures and utilities are usually performed with surveying instruments (precision levelling for vertical displacement and total stations for 3D geodetic facade monitoring), or with geotechnical instruments such as electronic liquid level gauges, electrolytic tilt sensors (electrolevels), surface clinometers/tiltmeters, precise taping, and crackmeters.

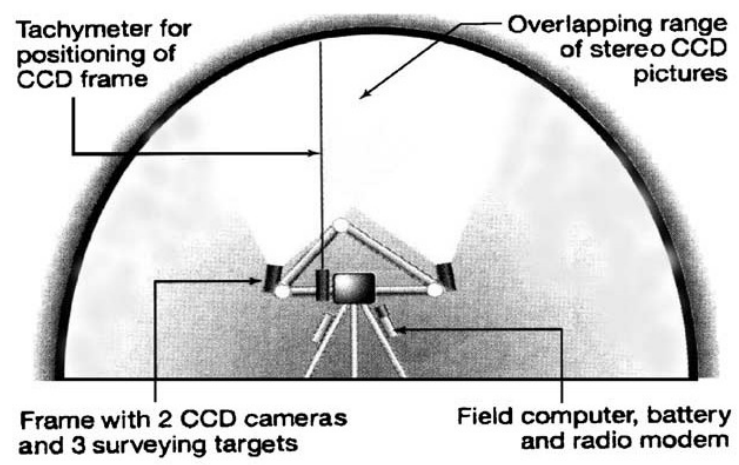

Figure 1. DIBIT Tunnel Profilometer

Third, measurements of deformation in the ground are performed with geotechnical instruments of the following types: single- or multi-point rod extensometers, magnetic extensometers, sliding micrometers, inclinometers, probe deflectometers (often called sliding curvometers) and deep settlement plates.

In addition, in order to ensure safety during excavation with the research result of Kovari and Amstrad [4] being quoted, it was mentioned that automation in the collection and processing of monitoring data is often necessary.

\subsection{Monitoring with Fiber Optic Sensors}

In this research, a mounted FBG (Fiber Bragg Grating) sensor technique is developed to measure the lining of Bai Ni-jing No. 3 Tunnel, in Yunnan Province, China as shown in Figure 2. 10 encapsulated FBGs are separately mounted on 5 monitoring points of each monitoring cross section by the cross-shaped layout, and one encapsulated FBG is free appended to compensate the local temperature on each arch crown [5].

\subsection{Time-Dependent Back Analysis}

This research is to develop a time-dependent back analysis method of a Multianchored Pile Retaining Wall (Figure 3). A multianchored pile retaining wall 
was constructed to protect the cut made for the cut and cover section of the twin Trojane Tunnel.

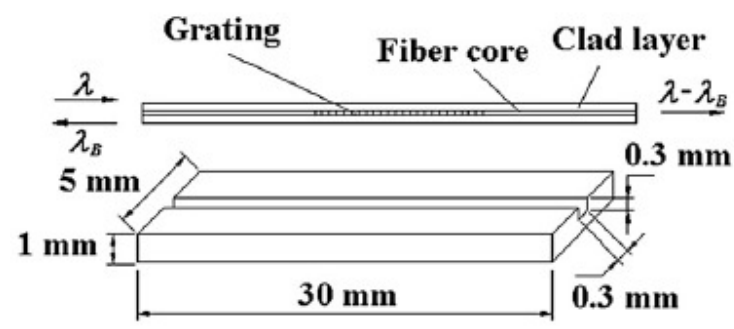

Figure 2. The Schematic Diagram of a FBC Encapsulated on the Metal Groove

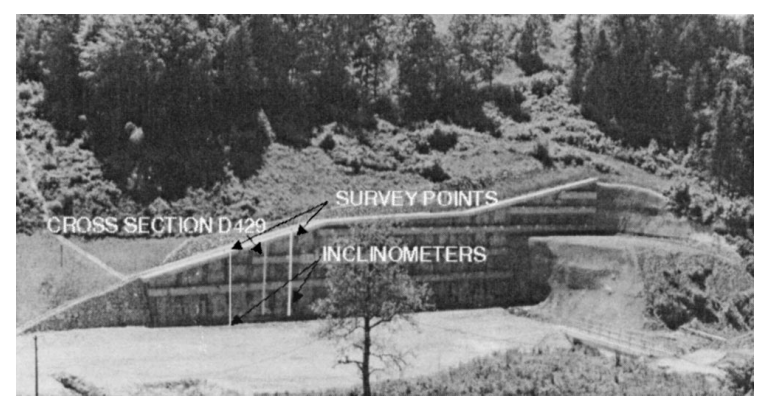

Figure 3. Front view of pile retaining wall at east end of Trojane Tunnel

Deformation monitoring surveys were conducted and measurements of movements were carried out throughout the construction cycle of the wall and beyond. In order to determine design parameters for the soil strata embedded in a complex geological sequence, the soil-wall interaction was back analyzed using the finite element method [6].

\subsection{Preliminary Conclusion}

In view of above-mentioned research, it could be learned that diversified monitoring techniques has been employed for monitoring tunnel deformation. In addition, for securing safety of the tunnel construction, it could also be learned that automated data collection is required as well. However, as these existing researches focus on measurement and monitoring for any limited specific fields of the individual tunnel, integrated automated data collection and status monitoring are not considered during the construction and maintenance stages of the diversified tunnels. Furthermore, wire-based measuring instrument has been utilized for automatic measurement but constant monitoring system based on 3D CAD foundation for tunnel monitoring during the construction and maintenance stages has not been developed. Therefore, the purpose of this study is to develop integrated tunnel monitoring system using wireless and automated data collection and 3D CAD system.

\section{MODULARIZATION \& INTEGRATION}

Different types of monitoring is required depending on the types and status of the tunnel and any monitoring item required for a certain tunnel is not necessarily required for other tunnel. Therefore, in this study, system modularization has been realized by employing the concept of 'Plug-in' for integrating the function of customizing to be complied with diversified tunnel characteristics [7].

Each SDA (Sensor-Data-Application) module includes database and application as shown on Figure 4 and each SDA module is registered at system library. Personnel in charge of relevant tunnel can plot specialized monitoring system for each tunnel by adding or eliminating individual module on the main frame. Additionally, in case of any need of a new monitoring, a module to be suitable for such monitoring can be developed and usable after it being registered at system library.

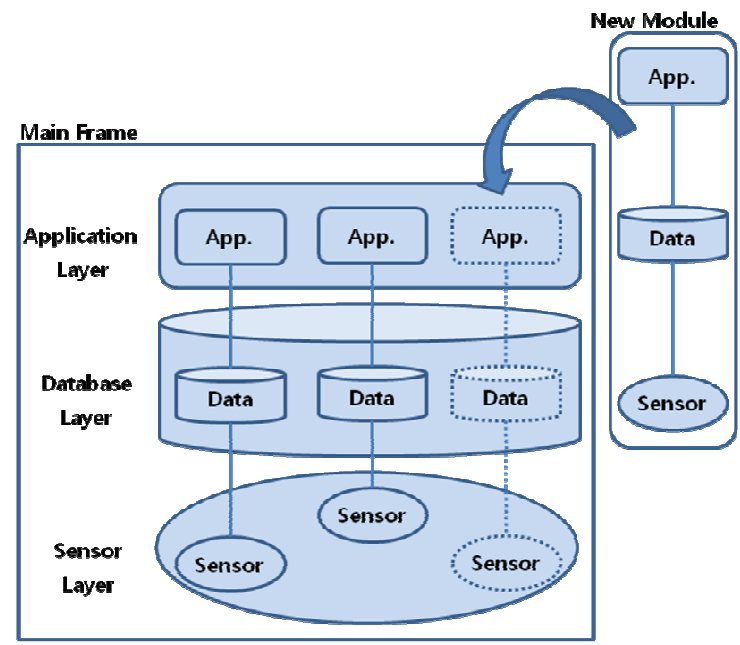

Figure 4. Architecture of Data Management System 


\section{AUTOMATED DATA COLLECTION}

In order to monitor tunnel, WADC(Wireless and Automated Data Collection) tool has been developed and this is corresponding to sensor part of SDA module. The structure of sensor part is as shown on Figure 5. Existing commercial application product is used for sensor. Analog signal of this sensor is converted into digital one and then its value is transmitted through wireless communication module in the sensor part. Zigbee was used for wireless communication and if necessary, communication distance can be extended by attaching amplifier.

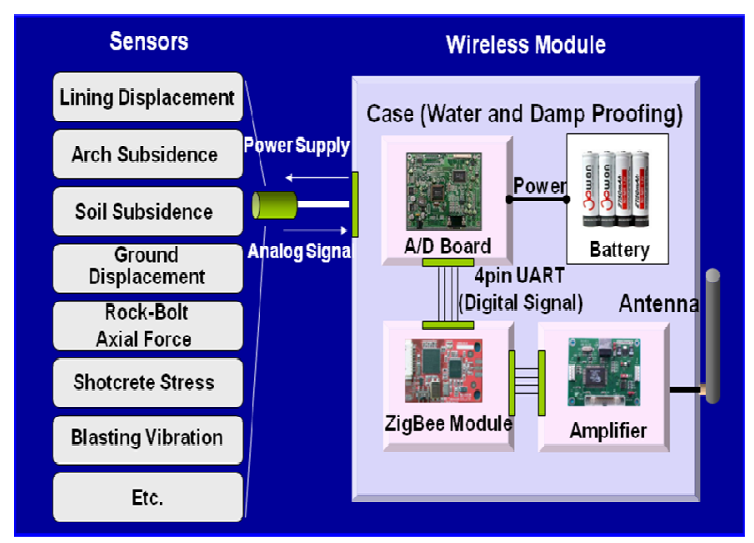

Figure 5. Structure of WADC Tool

In this study, two prototypes of module have been developed by using the concept of WADC tool. First prototype is to make existing sensor wireless module and second one is for blasting vibration sensor being directly developed by this study.

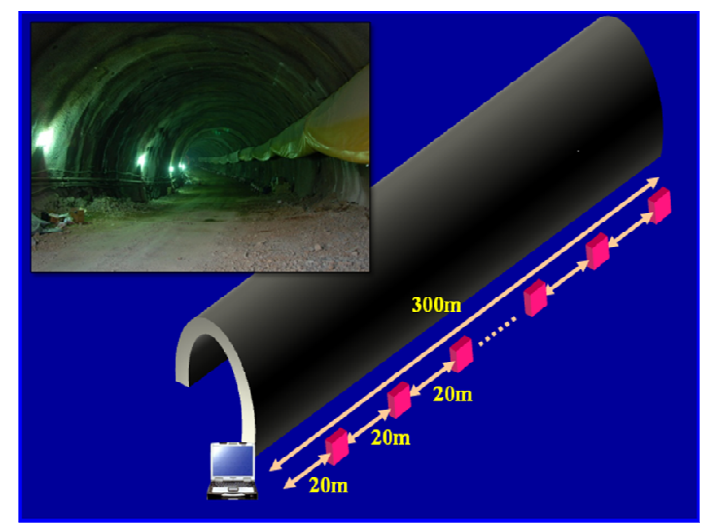

Figure 6. WADC Tool Test for Existing Sensors
Figure 6 is showing the experiment of first prototype for existing sensor with taking the tunnel currently under excavation as a case. Since A/D converting (Anlaog/Digital Converting) has been proved at laboratory experiment, performance of usefulness of installation and wireless communication on site has been tested.

15 numbers of wireless modules were installed with $20 \mathrm{~m}$ distance for the tunnel to be tested and were set to receive required data on 10 seconds intervals. Laptop PC and Zigbee coordinator were installed at pit mouth of the tunnel. As a result of this test, its installation time, comparing with existing one, was reduced by over $50 \%$ and wireless mesh network was successfully composed by smooth performance of Ad-hoc and multi-hopping of WADC tool. Stable data collection receiving was enabled.

Figure 7 is showing the field test of second prototype of WADC tool for the purpose of blasting vibration accelerometer being developed of its own by using MEMS (MicroElectroMechanical System) techniques.

This field test was carried out at the blasting section(50 m underground) of a city center subway construction site and its vibration around the surrounding foundation was monitored at the ground surface. Commercial sensor on the upper part of Figure 7 is Minimate Plus, VP-1220E and prototype is shown on the lower part of Figure 7.

According to the installation regulation of general blasting vibration sensor, it was allowed for a sensor to be positioned on a flat plane without any specific fixing apparatus if PPA (Peak Particle Acceleration) is below $0.2 \mathrm{~g}$. Therefore field monitoring was carried out accordingly as shown on Figure 7. Since this method is being generally applied in many cases at the site, smooth operation under this condition is important.

As a result of field test, vibration pattern and duration time $(3.5 \mathrm{sec}$.) were almost identical with those of the commercial sensor and wireless communication unstability and lost data were not evident. In addition, though a difference of $24 \%$ between $0.133 \mathrm{~g}$ for Vertical Peak Acceleration of commercial sensor and $0.101 \mathrm{~g}$ for that of tested 
prototype was observed. When considering the fact that tested prototype had been performed of its accurate operation at the time of laboratory calibration, rigid operation with ground surface was analyzed to be failed due to weight insufficiency of tested prototype. Insufficient weight will be reinforced at the time of future additional development.

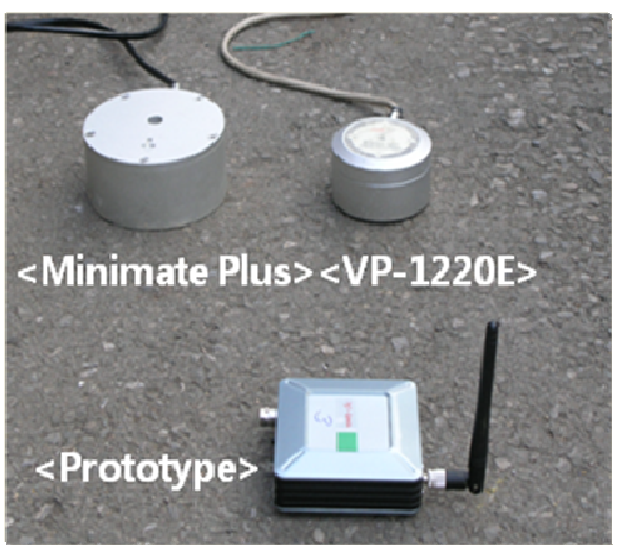

Figure 7. Field Test of Commercial Sensor and WADC Prototype

\section{3D BASED TUNNEL MONITORING SYSTEM}

The most efficient method of demonstrating sensed or measured tunnel deformation is to use 3 dimensional user interface. In this study, monitoring system by using 3D user interface was developed. This system is corresponding to data part, application part of SDA module. Figure 8 is showing a module for monitoring vibrating-wire strain sensor being installed in the tunnel that is desired to be controlled. At the right upper part of the figure, sensor location and measured value can be monitored through $3 \mathrm{D}$ view and at the right center part of the figure, measured value monitored by sensor can be confirmed in a real time. At the right lower part of the figure, it was arranged that the numerous measured values by sensor can be evaluated on a long term basis.

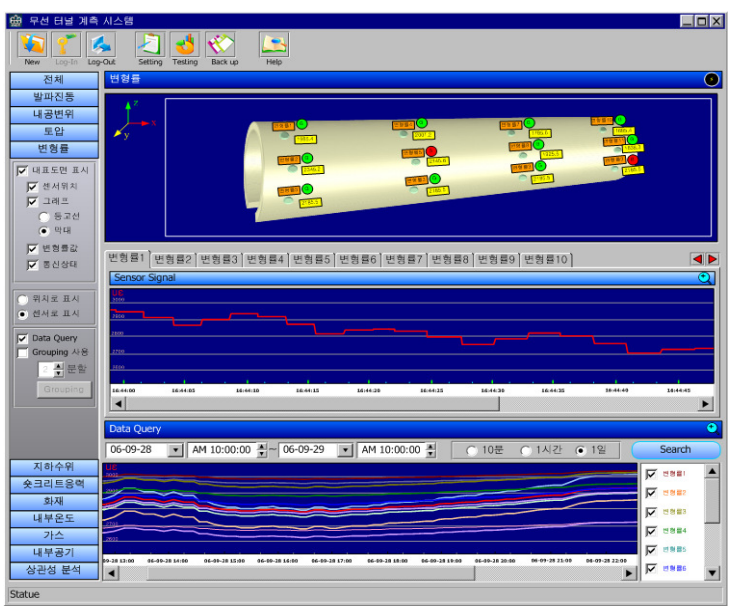

Figure 8. 3D Based User Interface

\section{CONCLUSIONS}

In this study, in order to develop data control system with flexibility so that integrated control of diversified type of tunnels may be ensured. SDA (Sensor-Data-Application) module of 'Plug-in' concept was developed. In addition, data collection process was automated by developing WADC (Wireless and Automated Data Collection) tool that is corresponding to sensor part of SDA module and by developing 3 dimensional user interface, it was arranged that sensed or measured tunnel deformation could be demonstrated most efficiently. Along with these efforts, it would be meaningful to note that a system that can be monitored by all the site administrator and head office management in an integrated way with ensuring customizing function by making commercial sensor to be in compliance with diversified tunnel features was developed.

\section{ACKNOWLEDGEMENTS}

This study was performed as a base project of Korea Institute of Construction Technology under the support of Ministry of Education, Science and Technology together with Ministry of Knowledge Economy.

\section{REFERENCES}

[1] Ministry of Land, Transport and Maritime Affairs (2007) 2007 Road Bridge and Tunnel Records, Ministry of Land, Transport and Maritime Affairs, Republic of Korea. 
[2] Michael J. Kavvadas (2005) Monitoring ground deformation in tunnelling: Current practice in transportation tunnels, Engineering Geology, Vol. 79, 93-113.

[3] Bock, H., (2001) European practice in geotechnical instrumentation for tunnel construction control, Tunnels and Tunnelling International, 51-54 (April).

[4] Kovari, K. and Amstrad, C. (1993) Decision making in tunnelling based on field measurements. In: Hudson, J. (Ed.), Comprehensive Rock Engineering, vol. 4, pp. 571-606 (Bergamon).

[5] Chuan Li et al. (2008) Monitoring second lining of tunnel with mounted fiber bragg grating strain sensors, Automation in Construction, Vol. 17, 641644.

[6] Jakob L. and Vladimir V. (2003) Time-Dependent Back Analysis of a Multianchored Pile Retaining Wall, Journal of Geotechnical and Geoenvironmental Engineering, Vol. 129, 91-95.

[7] Jung-Ryul Kim, Moon-Young Cho et al. (2007) Development of Automatic Tunnel Monitoring System to Prevent Structural Failures \& Collapses, Korea Institute of Construction Technology. 